DOI:10.5216/cab.v15i1.25777

\title{
CARACTERÍSTICAS FÍSICO-QUÍMICAS DA CARNE DE TOURINHOS ZEBUÍNOS E EUROPEUS ALIMENTADOS COM NÍVEIS DE GRÃO DE MILHETO NA DIETA
}

\author{
Rodrigo Medeiros da Silva ${ }^{1}$, JoÃo Restle ${ }^{2}$, Ubirajara Oliveira BileGo $^{3}$, Regis Luis Missio $^{4}$, \\ Paulo Santana PaCheCo ${ }^{5}$, CRistiano Sales PRADO ${ }^{6}$ \\ ${ }^{1}$ Pós-graduando da Universidade Federal de Goiás, Goiânia, GO, Brasil \\ ${ }^{2}$ Professor Visitante, Fundação Universidade Federal do Tocantins, Araguaína, TO, Brasil \\ ${ }^{3}$ Médico Veterinário, Mestre, Pesquisador do Centro Tecnológico Cooperativa Agroindustrial dos Produtores \\ Rurais do Sudoeste Goiano, Rio Verde, GO, Brasil. \\ ${ }^{4}$ Professor Doutor da Universidade Tecnológica Federal do Paraná, Pato Branco, PR, Brasil - \\ regisluismissio@gmail.com \\ ${ }^{5}$ Professor Doutor da Universidade Federal de Santa Maria, Santa Marias, RS, Brasil. \\ ${ }^{6}$ Professor Doutor da Universidade Federal de Goiás, Goiânia, GO, Brasil
}

\begin{abstract}
Avaliaram-se as características químico-físicas da carne de tourinhos mestiços com predominância genotípica europeia ou zebuína alimentados em confinamento com dietas com alta proporção de concentrado e níveis de grão de milheto em substituição ao de milho $(0,33,66$ e $100 \%$ ). Foram abatidos 24 tourinhos de cada predominância genética após 96 dias de confinamento. $\mathrm{O}$ delineamento experimental foi inteiramente casualizado, com os tratamentos em arranjo fatorial $4 \times 2$, utilizando-se seis repetições. As variáveis $\mathrm{pH}$ inicial $(6,7)$ e final $(5,9)$, a temperatura final $(9,72)$, a perda de líquidos ao descongelamento $(9,7 \%)$ e cocção $(26,6 \%)$, a cor $(3,7$
\end{abstract}

pontos), a textura ( 3,1 pontos), o marmoreio ( 4,5 pontos), a força ao cisalhamento das fibras musculares $\left(\mathrm{kgf} / \mathrm{cm}^{3}\right)$ e os teores de umidade $(72,9 \%)$, proteína bruta $(23,0 \%)$ e extrato etéreo $(1,5 \%)$ da carne não foram alterados pela substituição do grão de milho pelo de milheto. As características da carne não foram influenciadas pelas predominâncias genéticas, exceto o marmoreio, superior (4,99 vs 3,95 pontos) nos animais europeus. $\mathrm{O} \mathrm{pH}$ final da carcaça foi correlacionado com a perda de líquidos ao descongelamento $(r=-0,36)$ e a cor da carne $(r=-0,62)$. A substituição do grão de milho pelo de milheto na dieta de tourinhos não altera a qualidade da carne.

PALAVRAS-CHAVE: bovinos; gordura intramuscular; maciez da carne; perda de líquidos ao cozimento; zebuínos.

\section{MEAT PHYSICOCHEMICAL CHARACTERISTICS OF ZEBU AND EUROPEAN YOUNG BULLS FED GRAIN MILLET LEVELS IN THE DIET}

\section{ABSTRACT}

We evaluated the physicochemical characteristics of crossbred bulls with European or zebu genetic predominance fed in feedlot with diets with high concentrate $(80 \%)$ and grain millet levels to replace corn grain $(0,33,66$ and $100 \%)$. Twenty-four bulls of each genetic predominance were slaughtered after 96 days of confinement. The experimental design was completely randomized with treatments in a $4 \times 2$ factorial arrangement using six replicates. The variables initial (6.68) and final $\mathrm{pH}$ (5.9), final temperature of carcass $(9,7)$, fluid loss during thawing $(9.7 \%)$ and cooking $(26.6 \%)$, color $(3.7$ points), texture (3.1 points), marbling ( 4.5 points), shear strength of the muscle fibers $\left(\mathrm{kgf} / \mathrm{cm}^{3}\right)$, and moisture $(72.9 \%)$, crude protein $(23.0 \%)$ and ether extract content 
$(1.5 \%)$ of the meat were not affected by the replacement of corn grain by millet grain. Meat characteristics were not influenced by genetic predominance, except marbling, which was higher in European animals (4.99 vs. 3.95 points). Final $\mathrm{pH}$ was correlated with thawing loss $(\mathrm{r}=-$ $0.36)$ and meat color $(r=-0,62)$. The replacement of corn grain by grain of millet in the diet did not affect meat quality of young bulls.

KEYWORDS: cattle; fluid loss during cooking; intramuscular fat; meat tenderness; zebu.

\section{INTRODUÇÃO}

O Brasil está inserido no mercado internacional como um dos principais produtores $\mathrm{e}$ exportadores de carne bovina do mundo; todavia, os índices produtivos da pecuária brasileira ainda se encontram defasados em relação aos principais países produtores (1), demonstrando o grande potencial para aumento da produção de carne no país.

A estacionalidade na produção de forragem e a falta de planejamento nutricional estratégico permeiam como os principais entraves para o crescimento da produtividade, bem como da qualidade de carne, na medida em que determinam elevada idade de abate e inadequado acabamento de carcaça. Além disso, o fato de a maior parcela do rebanho brasileiro ser constituída por animais zebuínos compromete o atendimento da demanda por carne com melhores padrões de qualidade. Animais zebuínos são reconhecidamente produtores de carne com características físico-químicas (maciez, cor, textura, teor de gordura, etc.) menos desejáveis que animais europeus, fato associado não somente ao sistema de produção, mas também às características intrínsecas da carne (2).

A utilização estratégica do confinamento é uma alternativa para obtenção de incrementos de produtividade e qualidade de carne (3), notoriamente para sistemas de produção baseados em pastagens tropicais. Essa estratégia de manejo possibilita que as diferenças quanto às características da carne relacionadas ao grupo genético sejam minimizadas $(4,5)$, reflexo da redução da idade de abate e do melhor acabamento de carcaça.

O nível energético das dietas é um dos principais fatores determinantes do sucesso do período de terminação, influenciando o desempenho animal (6), bem como as características de carcaça e carne (7). No entanto, o aumento do nível energético representa, normalmente, elevação na proporção de concentrado da dieta, resultando em maiores custos com alimentação (6). Somando-se a isso, a elevação dos preços do grão de milho tem direcionado esforços na tentativa de encontrar alimentos alternativos que possam substituir total ou parcialmente o milho, sem comprometer o desempenho animal e as características de carcaça e carne, beneficiando a margem de lucro na terminação de bovinos em confinamento.

$\mathrm{O}$ grão de milheto, nesse sentido, tem se destacado na alimentação de ruminantes, tanto pelo menor preço em relação ao grão de milho, como pelo seu valor nutritivo. De forma geral é esperado que bovinos alimentados com grão de milheto e/ou misturas de grão de milho com grão de milheto tenham desempenho similar àqueles alimentados com dietas tradicionais, em que se utilizam grãos de milho ou sorgo (8); no entanto, pesquisas desenvolvidas no intuito de avaliar o efeito desse grão sobre as características da carne ainda são insipientes.

O objetivo deste trabalho foi avaliar as características físico-químicas da carne de bovinos mestiços com predominância genética europeia ou zebuína, alimentados com elevada proporção de concentrado e níveis de grão de milheto em substituição ao de milho.

\section{MATERIAL E MÉTODOS}

O trabalho foi desenvolvido entre agosto e novembro de 2010, no Setor de Bovinocultura de Corte do Centro Tecnológico da Cooperativa Agroindustrial dos Produtores Rurais do Sudoeste Goiano, município de Rio Verde/GO, localizado a $17^{\circ} 46^{\prime} 22^{\prime \prime}$ de latitude Sul e $51^{\circ} 02^{\prime} 86^{\prime \prime}$ de longitude Oeste e $815 \mathrm{~m}$ de altitude. O presente trabalho foi aprovado pelo CEEA/COEP/UFG, processo $111 / 2011$.

Foram utilizados 45 tourinhos com predominância genotípica europeia (predominância de raças continentais) e 44 com predominância genotípica zebuína, com peso médio inicial de 317,8 e $320,7 \mathrm{~kg}$, respectivamente, e idade média inicial avaliada pela dentição de 21 meses. Os animais, oriundos de leilão comercial, foram classificados quanto à predominância genética por profissional treinado, levando em consideração suas características fenotípicas, sendo os animais de cada predominância genética distribuídos aleatoriamente nas dietas experimentais (Tabela 1). 
Tabela 1 - Composição percentual e química das dietas

\begin{tabular}{|c|c|c|c|c|}
\hline \multirow{2}{*}{ Itens, $\%$ da matéria seca } & \multicolumn{4}{|c|}{$\%$ de milheto na dieta } \\
\hline & 0 & 33 & 66 & 100 \\
\hline Silagem de milho & 20,00 & 20,02 & 20,00 & 20,02 \\
\hline Milho & 70,50 & 48,96 & 25,06 & 0,00 \\
\hline Milheto & 0,00 & 24,05 & 49,88 & 77,47 \\
\hline Farelo de soja & 8,02 & 5,49 & 3,61 & 1,19 \\
\hline Uréia & 0,62 & 0,63 & 0,60 & 0,49 \\
\hline Núcleo mineral $^{1}$ & 0,86 & 0,85 & 0,85 & 0,83 \\
\hline Matéria seca, \% & 66,04 & 66,22 & 66,46 & 66,67 \\
\hline Proteína bruta & 14,19 & 14,16 & 14,45 & 14,18 \\
\hline Extrato etéreo & 3,36 & 2,82 & 5,46 & 6,64 \\
\hline FDNcp & 10,66 & 10,34 & 12,13 & 12,74 \\
\hline Nutrientes digestíveis totais & 78,91 & 78,48 & 77,54 & 77,22 \\
\hline
\end{tabular}

${ }^{\mathrm{I}}$ Níveis de garantia $(\mathrm{g} / \mathrm{kg}): \mathrm{Ca}=117-130 ; \mathrm{P}=61 ; \mathrm{S}=9 ; \mathrm{Na}=150 ; \mathrm{Mg}=694 ; \mathrm{Zn}=5,78 ; \mathrm{Mn}=1 ; \mathrm{Cu}=1,88 ; \mathrm{Co}=0,16 ; \mathrm{I}=0,165 ;$ $\mathrm{Se}=0,025 ;$ Monensina sódica $=2,4 ; \mathrm{FDNcp}=$ fibra em detergente neutro corrigida para cinzas e proteína.

Antecedendo o período experimental, os animais foram submetidos ao controle de endoparasitas e ectoparasitas, vacinados contra pasteurelose e adaptados às instalações e dietas por sete dias. Esses foram confinados em baias coletivas $(10 \times 7,70 \mathrm{~m})$, equipadas com bebedouros $\mathrm{e}$ comedouros e com piso de cascalho com declive de $5 \%$. Cada baia continha apenas animais da mesma predominância genética. O período experimental totalizou 89 dias, com alimentação à vontade (09h00 min e 17h00min), sendo as dietas balanceadas para ganho de peso de $1,5 \mathrm{~kg} / \mathrm{dia}$, estimando-se o consumo de $2,4 \%$ do peso corporal. O consumo de matéria seca foi de, respectivamente, 2,$25 ; 2,17 ; 2,30$ e $2,23 \%$ do peso corporal, enquanto que o consumo de nutrientes digestíveis totais foi de, respectivamente, 1,$78 ; 1,71 ; 1,79$ e $1,73 \%$ do peso corporal para as dietas com 0,33, 66 e $100 \%$ de grão de milheto. $\mathrm{O}$ ganho de peso médio diário foi de, respectivamente, 1,$75 ; 1,58 ; 1,75$ e $1,56 \mathrm{~kg}$ para os níveis de $0,33,66$ e $100 \%$ de grão de milheto na dieta, sendo superior nos tourinhos europeus em relação aos zebuínos $(2,10$ vs. 1,50 kg/dia).

Ao final do experimento, foram selecionados aleatoriamente seis animais de cada predominância genética nas diferentes dietas, os quais foram abatidos em frigorífico comercial com fiscalização do SIF, seguindo o fluxo normal na linha de abate. Antecedendo o abate, os animais foram submetidos a jejum de sólidos e líquidos por 14-16 horas. Após o abate, as carcaças foram identificadas, divididas ao meio, pesadas e levadas ao resfriamento por 24 horas em temperatura variando entre 0 e $2^{\circ} \mathrm{C}$. Antes e 24 horas após a refrigeração das carcaças foi registrado o pH do músculo Longissimus dorsi entre a $9^{\mathrm{a}}$ e $11^{\mathrm{a}}$ costelas, utilizando-se um potenciômetro portátil com eletrodo de inserção. Nessa mesma região, foi determinada a temperatura final da carcaça fria, avaliada 24 horas após o abate, utilizando-se um termômetro digital provido de haste metálica de inserção.

$\mathrm{Na}$ meia carcaça direita, foi retirada uma porção do músculo Longissimus dorsi, entre a $9^{\mathrm{a}} \mathrm{e}$ $11^{\mathrm{a}}$ costela, na qual foi determinado o grau de marmorização $(1$ a $3=\operatorname{traços;~} 4$ a $6=$ leve; 7 a $9=$ pequeno; 10 a $12=$ médio; 13 a $15=$ moderado; 16 a $18=$ abundante $)$, a textura das fibras musculares $(1=$ muito grosseira; 2 = grosseira; 3 = levemente grosseira; 4 = fina; 5 = muito fina) e a coloração após 30 minutos de exposição ao ar $(1=$ escura; $2=$ vermelho escura; 3 = vermelho levemente escuro; 4 = vermelha; 5 = vermelho-viva) (9). Em seguida, esse músculo foi embalado e identificado, sendo congelado a $-18^{\circ} \mathrm{C}$. Depois de 60 dias foram retirados, de cada porção cranial desse músculo, dois bifes com espessura de $2,5 \mathrm{~cm}$, sendo um desses congelado novamente para posterior análise química. Os bifes restantes foram pesados, identificados, colocados em bandejas de alumínio e descongelados durante 12 horas a $4^{\circ} \mathrm{C}$. Depois disso, os bifes foram pesados para obtenção da perda de peso durante o descongelamento. $\mathrm{Na}$ sequência, os bifes foram colocados em bandejas individuais, previamente pesadas, assados em forno elétrico até que a temperatura interna atingisse $70^{\circ} \mathrm{C}$. Depois, foram pesados, com e sem sua bandeja, para obtenção da perda de líquidos da carne durante o processo de cozimento.

A maciez da carne, avaliada pela resistência ao corte das fibras musculares, foi determinada nos bifes cozidos e resfriados por 24 horas a $4{ }^{\circ} \mathrm{C}$. Nestes, foram extraídos oito feixes circulares com 
$1,0 \mathrm{~cm}^{2}$ de área por bife, os quais foram cortados perpendicularmente à fibra, no aparelho WarnerBratzler Shear, e realizada a leitura da força para o cisalhamento das fibras musculares, desprezando-se o valor máximo e mínimo.

Os bifes destinados à análise química foram descongelados em temperatura ambiente, excluindose a gordura de cobertura, secos em estufa com ventilação forçada de $\operatorname{ar}\left(55^{\circ} \mathrm{C}\right)$ e moídos em moinho tipo Willey (partícula de $1 \mathrm{~mm}$ ). Nas amostras desses bifes foram determinados os teores de umidade, proteína bruta e extrato etéreo (10).

$\mathrm{O}$ delineamento experimental utilizado foi o inteiramente casualizado, com os tratamentos em arranjo fatorial $4 \times 2$, utilizando-se seis repetições. Os dados foram submetidos à análise de variância, correlação e regressão, considerando-se $\alpha=5 \%$.

O modelo matemático geral utilizado foi: $\gamma_{\mathrm{ijk}}$ $=\mu+\tau_{\mathrm{i}}+\beta_{\mathrm{j}}+(\tau \beta)_{\mathrm{ij}}+\mathfrak{f}_{\mathrm{k}}+\varepsilon_{\mathrm{ijk},}$, em que: $\gamma_{\mathrm{ijk}}=$ variável dependente; $\mu=$ média geral; $\tau_{\mathrm{i}}=$ efeito das dietas; $\beta_{\mathrm{j}}$ $=$ efeito do grupo genético $\mathrm{j} ;(\tau \beta)_{\mathrm{ij}}=$ interação entre dieta $\mathrm{i}$ e grupo genético $\mathrm{j} ; \varepsilon_{\mathrm{ijk}}=$ erro experimental residual. No estudo de regressão, o modelo foi: $\gamma_{\mathrm{ij}}=$ $\beta_{0}+\beta_{1} X_{i}+\beta_{2} X_{i}^{2}+\beta_{3} X_{i}^{3}+\alpha_{j}+\varepsilon_{i j}$, em que: $\gamma_{i j}=$ variáveis dependentes; $\beta$ 's $=$ coeficientes de regressão; $X_{i}=$ variáveis independentes; $\alpha_{j}=$ desvios da regressão; e $\varepsilon_{\mathrm{ij}}=$ erro aleatório residual.

\section{RESULTADOS E DISCUSSÃO}

Não foi verificada interação $(\mathrm{P}>0,05)$ entre as dietas e os grupos genéticos para as variáveis avaliadas. Da mesma forma, o $\mathrm{pH}$ da carcaça quente ( $\mathrm{pH}$ inicial) não foi alterado $(\mathrm{P}>0,05)$ pelas dietas (Tabela 2), fato possivelmente associado ao similar teor de glicogênio muscular ao abate. Tal pressuposição é suportada pelas características nutricionais das dietas e pelo fato de o consumo de matéria seca não ter sido alterado pela composição das dietas, o que certamente resultou em consumo de substratos neoglicogênicos e acúmulo de glicogênio muscular similares, tal como reportado por Lozano et al. (11).

Tabela 2. Características tecnológicas da carne de tourinhos mestiços com predominância europeia ou zebuína alimentados com níveis de grão de milheto na dieta

\begin{tabular}{|c|c|c|c|c|c|c|c|c|c|}
\hline \multirow{2}{*}{ GG } & \multicolumn{4}{|c|}{$\%$ de milheto na dieta } & \multirow{2}{*}{ Média } & \multirow{2}{*}{$\mathrm{CV}$} & \multicolumn{3}{|c|}{ Fontes de variação } \\
\hline & 0 & 33 & 66 & 100 & & & $\mathrm{M}$ & GG & $\mathrm{M}^{*} \mathrm{G}$ \\
\hline \multicolumn{10}{|c|}{ pH da carcaça quente } \\
\hline Europeu & 6,67 & 6,83 & 6,81 & 6,71 & 6,75 & & & & \\
\hline Zebuíno & 6,58 & 6,38 & 6,73 & 6,67 & 6,59 & 2,77 & 0,153 & 0,007 & 0,354 \\
\hline Média & 6,63 & 6,61 & 6,77 & 6,69 & 6,68 & & & & \\
\hline \multicolumn{10}{|c|}{$\mathrm{pH}$ da carcaça fria } \\
\hline Europeu & 5,91 & 5,97 & 5,90 & 5,84 & 5,91 & & & & \\
\hline Zebuíno & 5,82 & 5,91 & 5,96 & 5,94 & 5,91 & 4,19 & 0,915 & 0,835 & 0,724 \\
\hline Média & 5,86 & 5,94 & 5,93 & 5,89 & 5,91 & & & & \\
\hline \multicolumn{10}{|c|}{ Temperatura da carcaça fria, ${ }^{\circ} \mathrm{C}$} \\
\hline Europeu & 9,43 & 10,14 & 9,89 & 9,81 & 9,82 & & & & \\
\hline Zebuíno & 9,68 & 9,19 & 9,72 & 9,85 & 9,61 & 8,05 & 0,808 & 0,343 & 0,264 \\
\hline Média & 9,55 & 9,67 & 9,81 & 9,83 & 9,72 & & & & \\
\hline \multicolumn{10}{|c|}{ Perda de líquidos ao descongelamento, $\%$} \\
\hline Europeu & 6,74 & 11,72 & 7,70 & 11,59 & 9,44 & & & & \\
\hline Zebuíno & 8,90 & 10,28 & 10,87 & 10,03 & 10,03 & 30,37 & 0,093 & 0,338 & 0,142 \\
\hline Média & 7,82 & 11,00 & 9,29 & 10,81 & 9,73 & & & & \\
\hline \multicolumn{10}{|c|}{ Perda de líquidos ao cozimento, $\%$} \\
\hline Europeu & 25,57 & 27,52 & 25,57 & 27,56 & 26,56 & & & & \\
\hline Zebuíno & 26,34 & 29,05 & 22,78 & 27,56 & 26,65 & 16,63 & 0,094 & 0,791 & 0,632 \\
\hline Média & 25,96 & 28,29 & 24,18 & 27,98 & 26,60 & & & & \\
\hline
\end{tabular}

$\mathrm{M}=\%$ de milheto na dieta; $\mathrm{G}=$ grupo genético; $\mathrm{M} * \mathrm{G}=$ interação entre os fatores estudados. 
Quanto às predominâncias genéticas, verificou-se que tourinhos mestiços com predominância genética europeia apresentaram $\mathrm{pH}$ inicial superior $(\mathrm{P}<0,05)$ aos tourinhos mestiços com predominância genética zebuína (Tabela 2), o que pode estar relacionado à maior susceptibilidade ao estresse calórico de animais europeus em relação aos zebuínos. A variação do $\mathrm{pH}$ da carcaça está associada ao gasto de glicogênio muscular, em que o estresse pré-abate resulta na diminuição dos estoques de glicogênio, limitando a redução do $\mathrm{pH}$ do músculo (12, 13). Esses resultados foram discordantes dos obtidos por Lopes et al. (14), que verificaram menor $\mathrm{pH}$ inicial $(6,55)$ em tourinhos com predominância genética europeia (Red Norte) em relação aos tourinhos Nelore $(6,79)$, não sendo evidenciado os fatores de causa e efeito.

$\mathrm{O} \mathrm{pH}$ da carcaça 24 horas após o abate $(\mathrm{pH}$ final) não foi influenciado $(\mathrm{P}>0,05)$ pelos níveis de grão de milheto e predominância genética dos animais (Tabela 2), apesar do menor $\mathrm{pH}$ inicial nos animais zebuínos. Esses resultados demonstraram que o teor de glicogênio muscular antes do abate não foi limitante para a queda do $\mathrm{pH}$ nos animais europeus em relação aos animais zebuínos. Vale lembrar que a redução do $\mathrm{pH}$ é resultado da liberação de prótons $\left(\mathrm{H}^{+}\right)$durante a glicólise $(15)$, processo que tem o glicogênio como principal combustível para produção de energia anaeróbica durante o metabolismo muscular post mortem $(16,17)$.

Os resultados apresentados foram similares aos reportados por Rocha Junior et al. (18), os quais, avaliando as características da carcaça e carne de bovinos Nelore ou mestiços (1/2 Holandês 1/4 Gir $1 / 4$ Nelore), não verificaram alteração do $\mathrm{pH}$ final da carcaça. Por outro lado, Lopes et al. (14) verificaram que o $\mathrm{pH}$ final foi inferior em animais zebuínos, o que os autores associaram aos estoques de glicogênio muscular antes do abate. De certo modo, no que se refere às dietas experimentais, os resultados deste estudo foram similares aos verificados por Aferri et al. (19), que, ao avaliar o efeito de diferentes fontes de lipídios sobre alimentação de novilhos mestiços europeus, não verificaram variação do $\mathrm{pH}$ final, refletindo a ingestão de similares quantidades de precursores neoglicogênicos.

Os valores de $\mathrm{pH}$ (Tabela 2), avaliados 24 horas após abate, ficaram abaixo do valor limite $(6,0)$ considerado para ocorrência de carne tipo DFD (escura, consistente e não-exsudativa) (2). A avaliação do $\mathrm{pH}$ apresenta importância prática, pois está relacionada com variações nas características da carne. A queda do $\mathrm{pH}$ reduz a capacidade de retenção de água, bem como favorece a proteólise enzimática (20), o que, por um lado, favorece o amaciamento e, por outro, reduz a suculência da carne. Já a manutenção de $\mathrm{pH}$ mais elevado é acompanhada de um menor potencial de oxirredução, diminuindo a formação de oximioglobina (21), responsável pela cor vermelho brilhante da carne. Tais aspectos foram evidenciados a partir das correlações (Tabela 3) do pH final com a força ao cisalhamento das fibras musculares $(r=$ $0,58)$, textura $(r=-0,51)$ e coloração da carne $(r=$ $0,62)$.

A temperatura da carcaça, avaliada 24 horas após o abate, não foi influenciada $(\mathrm{P}>0,05)$ pelos níveis de grão de milheto nem pelas predominâncias genéticas (Tabela 2). Os valores obtidos foram superiores à temperatura máxima recomendada $\left(5{ }^{\circ} \mathrm{C}\right)$, como garantia de manter a qualidade microbiológica da carne (22). Vale destacar que as condições internas da câmara fria podem variar em função do tempo, podendo inclusive atuar de forma diferente sobre as características da carne em função da quantidade e disposição das carcaças na câmara fria (23). Em outras palavras, é importante ressaltar que a temperatura de resfriamento está diretamente relacionada com o pH da carcaça, em que maiores temperaturas favorecem a glicólise, induzindo, assim, uma elevada taxa de formação de lactato e queda do $\mathrm{pH}$ (24).

No presente estudo, no entanto, não foi verificada correlação $(\mathrm{P}>0,05)$ entre a temperatura e o pH final da carcaça (Tabela 3). Considerando o exposto, as temperaturas finais semelhantes das carcaças, explicam, em parte, o $\mathrm{pH}$ final, indicando, por outro lado, que o glicogênio muscular foi determinante para as variações do $\mathrm{pH}$ da carcaça. Além disso, considerando que a temperatura final da carcaça apresentou em média $9,72{ }^{\circ} \mathrm{C}$, é provável que a temperatura durante $\mathrm{o}$ resfriamento não tenha reduzido bruscamente $\left(<10 \quad{ }^{\circ} \mathrm{C}\right)$ antes das 10 primeiras horas após a sangria, o que pode ter evitado o encurtamento das fibras musculares pelo frio (25).

Os níveis de grão de milheto em substituição ao de milho da dieta e as predominâncias genéticas não influenciaram $(\mathrm{P}>0,05)$ a perda de líquidos durante o descongelamento e cocção (Tabela 2). Avaliando as características da carne de diferentes grupos genéticos (Nelore, 1/2 Limousin $+1 / 2$ Nelore ou 1/2 Red Angus + 1/2 Nelore) e acabamentos de carcaça (3 e $5 \mathrm{~mm}$ ), Moggioni et al. (26) verificaram que, no menor grau de acabamento, o grupo genético Nelore apresentou as menores perdas de água tanto no descongelamento quanto na cocção em comparação aos demais grupos, que apresentaram similaridade para essa característica. No maior acabamento, no entanto, não foi verificada diferença 
entre os três grupos genéticos. Os autores atribuíram a menor perda de líquidos da carne dos tourinhos Nelore em razão do maior $\mathrm{pH}$ da carcaça, que teria sido maior nesse genótipo. A presença de fluídos no músculo é resultado da capacidade de retenção de água a partir das proteínas musculares, particularmente da miofibrila, que pode unir grande quantidade de água por pontes de hidrogênio aos grupos polares das proteínas. A quantidade de água diminui conforme os grupos polares são bloqueados. Assim, quando a glicólise post mortem ocorre de forma mais rápida, se obtém um $\mathrm{pH}$ menor a uma temperatura mais elevada, diminuindo a capacidade de retenção de água (20).

Tabela 3. Matriz de correlação para as características da carne de novilhos alimentados com níveis de grão de milheto em substituição ao grão de milho da dieta

\begin{tabular}{|c|c|c|c|c|c|c|c|c|c|c|c|c|}
\hline & & pHf & $\mathrm{pHi}$ & $\mathrm{Tf}$ & PD & $\mathrm{PC}$ & Cor & Tex & Mar & $\mathrm{FC}$ & $\mathrm{U}$ & PB \\
\hline \multirow{2}{*}{$\mathrm{pHi}$} & $\mathrm{r}$ & 0,12 & & & & & & & & & & \\
\hline & $\mathrm{P}$ & 0,436 & & & & & & & & & & \\
\hline \multirow{2}{*}{$\mathrm{Tf}$} & $\mathrm{r}$ & $-0,11$ & 0,12 & & & & & & & & & \\
\hline & $\mathrm{P}$ & 0,471 & 0,446 & & & & & & & & & \\
\hline \multirow{2}{*}{ PD } & $\mathrm{r}$ & $-0,36$ & $-0,06$ & $-0,16$ & & & & & & & & \\
\hline & $\mathrm{P}$ & 0,014 & 0,702 & 0,296 & & & & & & & & \\
\hline \multirow{2}{*}{ PC } & $\mathrm{r}$ & $-0,48$ & $-0,07$ & 0,02 & 0,34 & & & & & & & \\
\hline & $\mathrm{P}$ & 0,001 & 0,671 & 0,870 & 0,021 & & & & & & & \\
\hline \multirow{2}{*}{ Cor } & $\mathrm{r}$ & $-0,62$ & $-0,12$ & $-0,12$ & 0,68 & 0,55 & & & & & & \\
\hline & $\mathrm{P}$ & $<0,001$ & 0,410 & 0,413 & $<0,001$ & $<0,001$ & & & & & & \\
\hline \multirow[b]{2}{*}{ Tex } & $\mathrm{r}$ & $-0,51$ & $-0,31$ & 0,15 & 0,37 & 0,34 & 0,67 & & & & & \\
\hline & $\mathrm{P}$ & $<0,001$ & 0,037 & 0,323 & 0,061 & 0,062 & $<0,001$ & & & & & \\
\hline \multirow{2}{*}{ Mar } & $\mathrm{r}$ & 0,12 & 0,22 & 0,14 & $-0,14$ & 0,05 & $-0,06$ & 0,02 & & & & \\
\hline & $\mathrm{P}$ & 0,439 & 0,135 & 0,348 & 0,360 & 0,748 & 0,734 & 0,915 & & & & \\
\hline \multirow{2}{*}{ FC } & $\mathrm{r}$ & 0,58 & $-0,12$ & $-0,10$ & 0,54 & 0,63 & 0,55 & 0,27 & $-0,06$ & & & \\
\hline & $\mathrm{P}$ & $<0,001$ & 0,438 & 0,499 & $<0,001$ & $<0,001$ & $<0,001$ & 0,111 & 0,683 & & & \\
\hline \multirow{2}{*}{$\mathrm{U}$} & $\mathrm{r}$ & $-0,01$ & $-0,27$ & 0,08 & $-0,38$ & 0,16 & $-0,11$ & $-0,04$ & 0,30 & $-0,14$ & & \\
\hline & $\mathrm{P}$ & 0,934 & 0,072 & 0,586 & 0,009 & 0,292 & 0,468 & 0,809 & 0,044 & 0,350 & & \\
\hline \multirow{2}{*}{ PB } & $\mathrm{r}$ & $-0,12$ & 0,02 & $-0,08$ & $-0,04$ & 0,02 & $-0,23$ & $-0,11$ & 0,03 & 0,16 & $-0,17$ & \\
\hline & $\mathrm{P}$ & 0,411 & 0,866 & 0,583 & 0,795 & 0,885 & 0,115 & 0,466 & 0,827 & 0,299 & 0,249 & \\
\hline \multirow{2}{*}{ EE } & $\mathrm{r}$ & 0,14 & $-0,15$ & $-0,10$ & $-0,09$ & 0,01 & $-0,04$ & 0,08 & $-0,05$ & $-0,18$ & $-0,02$ & $-0,06$ \\
\hline & $\mathrm{P}$ & 0,337 & 0,316 & 0,596 & 0,539 & 0,920 & 0,794 & 0,572 & 0,749 & 0,217 & 0,883 & 0,675 \\
\hline
\end{tabular}

$\mathrm{pHi}$ e $\mathrm{pHf}=\mathrm{pH}$ inicial e final da carcaça, respectivamente; $\mathrm{Tf}=$ temperatura final da carcaça; $\mathrm{PD}=$ perda de líquidos ao descongelamento; $\mathrm{PC}=$ perda de líquidos à cocção; $\mathrm{Tex}=$ textura; $\mathrm{Mar}=$ marmoreio; $\mathrm{FC}=$ força ao cisalhamento das fibras musculares; $\mathrm{U}, \mathrm{PB}$ e EE = teor de umidade, proteína bruta e extrato etéreo da carne, respectivamente.

No presente estudo, a perda de líquidos ao descongelamento e cocção foi significativamente correlacionada (Tabela 3) com o pH final da carcaça $(\mathrm{r}=-0,36$ e $\mathrm{r}=-0,48$, respectivamente) e coloração da carne $(\mathrm{r}=0,68$ e $\mathrm{r}=0,55$; respectivamente). Os resultados apresentados foram coerentes ao exposto por Osório et al. (27): o aumento da retenção de água, em função do maior $\mathrm{pH}$, determina menor dispersão da luz pela estrutura da carne, tornando-a mais escura. Da mesma forma, Moggioni et al. (26) relacionaram a pior coloração e o maior $\mathrm{pH}$ da carne de tourinhos Nelore à maior retenção de água em relação aos tourinhos mestiços $1 / 2$ Limousin $+1 / 2$ Nelore e 1/2 Red Angus + 1/2 Nelore. Além disso, verificou-se moderada correlação $(\mathrm{P}<0,05)$ entre a perda de líquidos ao descongelamento e cocção $(\mathrm{r}=$ 
0,34 ), indicando que bifes que perderam mais líquidos ao resfriamento tenderam a perder mais água também ao cozimento. Dentre os aspectos relacionados com a perda de líquidos, tem-se o efeito sobre a palatabilidade da carne, que varia inversamente com a perda de líquidos. O principal aspecto que influencia a perda de líquidos e, consequentemente, a palatabilidade está relacionado com o processo de cocção (28), em que processos de cocção que produzem maior retenção de fluídos originam, de forma geral, carnes mais palatáveis.
Dessa forma, o tempo de preparo, a temperatura, a pressão e a umidade do meio são determinantes sobre a perda de líquidos ao cozimento.

A cor da carne não foi alterada $(\mathrm{P}>0,05)$ pelos níveis de milheto na dieta, nem pelo grupo genético dos animais (Tabela 4). Essa característica está principalmente associada com o peso corporal e/ou idade dos animais, já que a quantidade de mioglobina circulante aumenta com o avanço da idade (29) e raramente em função da dieta (30).

Tabela 4. Características físico-químicas da carne de tourinhos mestiços com predominância europeia e zebuína alimentados com níveis de grão de milheto na dieta

\begin{tabular}{|c|c|c|c|c|c|c|c|c|c|}
\hline \multirow{2}{*}{ GG } & \multicolumn{4}{|c|}{$\%$ de milheto na dieta } & \multirow{2}{*}{ Média } & \multirow{2}{*}{$\mathrm{CV}$} & \multicolumn{3}{|c|}{ Fontes de variação } \\
\hline & 0 & 33 & 66 & 100 & & & $\mathrm{M}$ & GG & $\mathrm{M}^{*} \mathrm{G}$ \\
\hline \multicolumn{10}{|c|}{ Cor, pontos ${ }^{1}$} \\
\hline Europeu & 2,59 & 3,39 & 2,78 & 3,19 & 2,99 & & & & \\
\hline Zebuíno & 3,40 & 3,62 & 3,54 & 3,48 & 3,51 & 43,40 & 0,153 & 0,341 & 0,238 \\
\hline Média & 2,99 & 3,51 & 3,17 & 3,34 & 3,70 & & & & \\
\hline \multicolumn{10}{|c|}{ Textura, pontos ${ }^{1}$} \\
\hline Europeu & 3,04 & 2,89 & 2,58 & 3,12 & 2,91 & & & & \\
\hline Zebuíno & 3,06 & 3,53 & 3,18 & 3,14 & 3,23 & 21,28 & 0,672 & 0,163 & 0,583 \\
\hline Média & 3,05 & 3,21 & 2,88 & 3,13 & 3,07 & & & & \\
\hline \multicolumn{10}{|c|}{ Marmoreio, pontos ${ }^{2}$} \\
\hline Europeu & 5,58 & 4,64 & 4,80 & 4,94 & 4,99 & & & & \\
\hline Zebuíno & 3,48 & 3,42 & 3,37 & 5,49 & 3,95 & 20,99 & 0,311 & 0,038 & 0,329 \\
\hline Média & 4,54 & 4,03 & 4,09 & 5,22 & 4,47 & & & & \\
\hline \multicolumn{10}{|c|}{ Força ao cisalhamento das fibras musculares (FC), kgf } \\
\hline Europeu & 6,10 & 7,80 & 7,23 & 9,62 & 7,69 & & & & \\
\hline Zebuíno & 7,97 & 9,47 & 7,59 & 9,07 & 8,53 & 28,48 & 0,066 & 0,239 & 0,535 \\
\hline Média & 7,04 & 8,64 & 7,42 & 9,35 & 8,11 & & & & \\
\hline
\end{tabular}

$\mathrm{M}=\%$ de milheto na dieta; $\mathrm{G}=$ grupo genético; $\mathrm{M}^{*} \mathrm{G}=$ interação entre fatores; ${ }^{2}$ Variação de 1 a 5 pontos, sendo $1=$ textura muito grosseira e coloração escura e 5= textura muito fina e coloração vermelha viva; ${ }^{3}$ Variação de 1 a 18 pontos, sendo $1-3=$ traços e $16-$ $18=$ abundante.

A carne dos animais experimentais (Tabela 4), independente das dietas e grupos genéticos, foi classificada como "vermelha levemente escura", podendo ser considerada normal para a categoria estudada. Avaliando a carne de novilhos 1/2 Purunã 1/2 Canchim, castrados ou não, abatidos em idade jovem (26 meses) ou superjojvem (16 meses), Kuss et al. (31) verificaram que a cor da carne não foi alterada pela idade de abate, sendo classificada como "vermelha" (4,1 pontos) nos castrados e "vermelha levemente escura" (3,0 pontos) nos inteiros.
Avaliando a carne de novilhos mestiços $5 / 8$ Charolês 3/8 Nelore ou 5/8 Nelore 3/8 Charolês, jovens (15,2 meses) ou superjovens (22,8 meses), Pacheco et al. (4) não verificaram efeito da idade de abate e do grupo genético, sendo a carne classificada como "vermelha" (4,4 pontos); entretanto, os animais eram castrados. Já Missio et al. (7), avaliando as características da carcaça e carne de tourinhos superjovens (14-16 meses), mestiços CharolêsNelore, alimentados com níveis de concentrado (22, 40,59 e $79 \%$ ), verificaram melhora da cor da carne 
com o avanço do teor de concentrado, passando de uma carne classificada como "vermelha levemente escura" (3,5 pontos) para "vermelho vivo" $(5,0$ pontos), reflexo da redução da idade de abate $(16,6$ para 14,8 meses). Segundo esses autores, a cor é uma das principais características que influencia $o$ consumidor no momento da compra, pois colorações mais escuras estão associadas à deterioração da carne, e a melhora desta característica beneficia também os vendedores finais, que terão maior saída deste produto e consequentemente maior giro de capital.

O nível de grão de milheto em substituição ao de milho da dieta e o grupo genético dos animais não influenciaram $(\mathrm{P}>0,05)$ a textura da carne (Tabela 4). A textura é avaliada por meio da granulação que a superfície do músculo apresenta quando cortada, uma vez que o músculo é constituído por um conjunto de fibras musculares agrupadas em fascíolos envolvidos por uma tênue camada de tecido conectivo, o perimísio (9). Segundo esse autor, a variação da textura da carne está mais associada com a idade dos animais, em que bovinos jovens apresentam carne com textura mais fina e mais macia que aqueles de maior idade. Isso foi evidenciado no presente estudo pela correlação existente entre a textura e a coloração da carne $(r=0,67)$, indicando que carnes com coloração "vermelha brilhante", característico de animais jovens, apresentam textura fina.

Avaliando níveis de concentrado na dieta de bovinos superjovens, Missio et al. (7) verificaram que a textura da carne passou de levemente grosseira, no menor nível de concentrado (22\%), para textura fina, no maior nível de concentrado (79\%), resultados que foram associados à redução da idade de abate. Assim, parece que os efeitos da alimentação apresentam maior impacto sobre a textura da carne quando alteram a curva de crescimentos dos animais, alterando a deposição dos tecidos corporais e a maturidade fisiológica da carcaça. Isso de certa maneira também se reflete nas diferenças entre grupos genéticos distintos, já que, de forma geral, a uma mesma idade cronológica, animais de origem Bos taurus indicus apresentam maior idade fisiológica que bovinos Bos taurus taurus, como resultado do menor peso adulto, apresentando textura da carne mais grosseira, tal como demonstrado em Wheeler et al. (32). No entanto, Cattelan et al. (33), avaliando diferentes frequências de alimentação para vacas de descarte ou novilhos de diferentes grupos genéticos, verificaram interação significativa entre categoria animal e grupo genético, em que novilhos 5/8 Charolês $3 / 8$ Nelore apresentaram carne com textura próxima de fina $(3,83$ pontos), que tem boa aceitação pelo mercado consumidor, enquanto que novilhos $5 / 8$ Nelore $3 / 8$ Charolês apresentaram pior pontuação $(2,67$ pontos $=$ textura grosseira). Nas vacas de descarte não houve diferença entre os grupos genéticos para a textura da carne $(2,96$ pontos $=$ levemente grosseira), inferindo que as diferenças relacionadas ao genótipo acabam desaparecendo com o avanço da idade.

A força de cisalhamento, nesse sentido, não foi alterada $(\mathrm{P}>0,05)$ pelo nível de grão de milheto na dieta e grupo genético dos animais (Tabela 4), variando de 7,04 a $9,35 \mathrm{kgf} / \mathrm{cm}^{3}$. Os valores obtidos no presente estudo foram superiores aos verificados por Miotto et al. (34), que avaliaram níveis de substituição do grão de milho pelo farelo do mesocarpo do babaçu $(0,25,50,75$ e 100) e verificaram aumento da força ao cisalhamento das fibras musculares $\left(5,5 ; 7,5 ; 9,1 ; 10,8\right.$ e $\left.10,5 \mathrm{kgf} / \mathrm{cm}^{3}\right)$ de tourinhos da raça Nelore com idade similar aos deste estudo. Todavia, no estudo citado, ocorreu alteração na deposição de tecidos corporais da carcaça (especialmente gordura) em função da inclusão do referido subproduto, o que pode ter comprometido a maciez da carne. A explicação para os elevados valores de força de cisalhamento encontrados neste estudo talvez esteja nas correlações (Tabela 3) dessa característica com a perda de líquidos ao descongelamento $(\mathrm{r}=0,54$; $\mathrm{P}$ $<0,001)$, perda de líquidos à cocção $(r=0,63$; $\mathrm{P}<0,001)$ e cor da carne $(\mathrm{r}=0,55 ; \mathrm{P}<0,001)$. As correlações demonstraram que o ponto crucial para a maciez da carne esteve envolvido com a redução do $\mathrm{pH}$ durante o resfriamento, incorrendo em um incompleto desenvolvimento do rigor mortis, limitado possivelmente pelo teor de glicogênio muscular.

Quanto ao grupo genético, alguns autores têm verificado aumento na dureza da carne com o aumento do grau de sangue de animais zebuínos ao genótipo $(35,36)$. Segundo Lima Junior et al. (37), a menor maciez da carne de zebuínos, em relação às raças europeias, está relacionada com a idade de abate e o número de ligações cruzadas termoestáveis do colágeno dos músculos. Além disso, a maior concentração de calpastastina no músculo de zebuínos, a qual atua como inibidor de enzimas proteolíticas do grupo calpaína, diminuindo a lise da célula durante a transformação do músculo em carne, contribui para a menor maciez da carne (38). Todavia, tem se verificado que a utilização do confinamento associado à terminação dos animais 
em idades mais jovens tem possibilitado similar força de cisalhamento das fibras musculares entre animais europeus e zebuínos $(4,5)$, embora isso não seja consenso na literatura (39). Segundo Hadlich et al. (5), o abate de animais jovens foi uma alternativa vantajosa, pois a quantidade e a solubilidade do colágeno não comprometeu a maciez da carne, independentemente do grupo genético dos animais.

A quantidade de gordura intramuscular ou marmoreio não foi influenciada $(\mathrm{P}>0,05)$ pelo nível de substituição do milho pelo grão de milheto (Tabela 4), resultado do similar consumo de energia. Esses resultados foram coerentes com o exposto por Pethick et al. (40), em que o marmoreio da carne está diretamente associado ao consumo total de energia pelo animal. Além disso, segundo esses autores, a maior deposição de gordura intramuscular ocorre em dietas que promovem maiores precursores neoglicogênicos, visto que essa gordura tem preferência por carbonos provenientes da glicose e lactato.

O marmoreio foi $26 \%$ superior $(\mathrm{P}<0,05)$ nos animais europeus em relação aos animais zebuínos (Tabela 4). Esses resultados foram discordantes dos verificados por outros estudos $(4,33)$, os quais avaliaram as características da carne de diferentes categorias e grupos genéticos e não verificaram diferença da marmorização da carne de novilhos $5 / 8$ Charolês 3/8 Nelore em relação aos animais 5/8 Nelore 3/8 Charolês. Da mesma maneira, Vaz et al. (41) não verificaram diferença para o grau de marmorização da carne de novilhos castrados dos grupos genéticos 3/4 Charolês $1 / 4$ Nelore ou 3/4 Nelore 1/4 Charolês. Considerando que animais zebuínos são mais velhos que animais europeus à uma mesma idade cronológica, seria esperado que estes genótipos apresentassem maior teor de gordura intramuscular, visto que essa é a última gordura a ser depositada na carcaça (40). No entanto, os animais europeus apresentaram maior ganho de peso que os zebuínos (2,10 vs $1,50 \mathrm{~kg} /$ dia $)$, o que justifica os resultados encontrados.

O marmoreio é um indicador importante da qualidade da carne. Em estudo relacionado (42) verificou-se que o aumento do marmoreio reduziu a perda de líquido ao cozimento, inibiu o encurtamento das fibras musculares pelo frio, aumentou a solubilidade do colágeno e melhorou a maciez da carne bovina. No presente estudo, no entanto, o marmoreio não foi correlacionado $(\mathrm{P}>0,05)$ com nenhuma das variáveis estudadas (Tabela 3), inferindo que outros fatores foram mais importantes sobre a variação das características da carne.

Os teores de umidade, proteína bruta e extrato etéreo da carne não foram influenciados $(\mathrm{P}>0,05)$ pelos níveis de grão de milheto $\mathrm{e}$ predominância genética dos animais (Tabela 5). Os valores obtidos para o teor de umidade foram similares aos verificados na literatura $(43,44)$. Vale destacar, no entanto, que o teor de umidade da carne está diretamente relacionado com o teor de gordura e, consequentemente, com a nutrição e idade do animal, entre outros fatores, reduzindo à medida que aumenta o depósito desse tecido na carcaça, haja vista que o tecido adiposo apresenta menor teor de água que o tecido muscular $(43,45)$. Entretanto, a gordura influencia na retenção de líquidos da carne, diminuindo a perda de líquidos pela proteção física exercida, o que, a certo grau de acabamento, pode resultar em efeito equivalente àquele relacionado com o teor de água na gordura. No presente estudo, esperava-se, em função do maior marmoreio dos animais europeus, maiores teores de umidade da carne. Todavia, pela análise de correlação (Tabela 3), verificou-se que o teor de umidade apresentou baixa correlação $(\mathrm{P}<0,05)$ com o marmoreio $(\mathrm{r}=0,30)$ e perda de líquidos ao descongelamento $(r=-0,38)$, demonstrando que a variação no teor de gordura intramuscular e a perda de líquidos foram equivalentes e não suficientes para alterar o teor de umidade da carne.

Apesar do teor de proteína bruta não apresentar grandes variações na carne bovina, os valores médios encontrados neste estudo foram superiores aos encontrados por Abrahão et al (43) e Fernandes et al. (44), enquanto que os valores obtidos para os teores de extrato etéreo foram inferiores aos obtidos por 43 e 44, o que possivelmente está relacionado com o grau de acabamento das carcaças. O teor de extrato etéreo é o componente mais variável da carne, estando diretamente associado com a quantidade de gordura da carcaça (43). Todavia, apesar de ter-se verificado diferença no teor de marmoreio da carne entre as predominâncias genéticas dos animais experimentais, não foi verificada correlação do teor de extrato etéreo da carne com o grau de marmoreio, bem como com nenhuma das variáveis estudadas. 
Tabela 5. Composição química da carne de novilhos mestiços com predominância genética europeia ou zebuína alimentados com níveis de grão de milheto na dieta

\begin{tabular}{|c|c|c|c|c|c|c|c|c|c|}
\hline \multirow{2}{*}{ GG } & \multicolumn{4}{|c|}{$\%$ de milheto na dieta } & \multirow{2}{*}{ Média } & \multirow{2}{*}{$\mathrm{CV}$} & \multicolumn{3}{|c|}{ Fontes de variação } \\
\hline & 0 & 33 & 66 & 100 & & & $\mathrm{M}$ & GG & $\mathrm{M}^{*} \mathrm{G}$ \\
\hline \multicolumn{10}{|c|}{ Umidade, $\%$} \\
\hline Europeu & 73,25 & 72,45 & 73,90 & 72,82 & 73,10 & \multirow{3}{*}{1,40} & \multirow{3}{*}{0,961} & \multirow{3}{*}{0,131} & \multirow{3}{*}{0,270} \\
\hline Zebuíno & 72,41 & 73,14 & 72,11 & 72,92 & 72,64 & & & & \\
\hline Média & 72,83 & 72,80 & 73,01 & 72,86 & 72,87 & & & & \\
\hline \multicolumn{10}{|c|}{ Proteína bruta, $\%$} \\
\hline Europeu & 23,07 & 23,16 & 22,64 & 23,09 & 22,99 & \multirow{3}{*}{3,39} & \multirow{3}{*}{0,055} & \multirow{3}{*}{0,905} & \multirow{3}{*}{0,605} \\
\hline Zebuíno & 23,40 & 22,99 & 22,26 & 23,42 & 23,02 & & & & \\
\hline Média & 23,23 & 23,07 & 22,46 & 23,26 & 23,00 & & & & \\
\hline \multicolumn{10}{|c|}{ Extrato etéreo, $\%$} \\
\hline Europeu & 1,83 & 1,36 & 1,13 & 1,43 & 1,44 & \multirow{3}{*}{22,37} & \multirow{3}{*}{0,178} & \multirow{3}{*}{0,763} & \multirow{3}{*}{0,809} \\
\hline Zebuíno & 1,62 & 1,66 & 1,15 & 1,67 & 1,53 & & & & \\
\hline Média & 1,73 & 1,51 & 1,14 & 1,55 & 1,48 & & & & \\
\hline
\end{tabular}

$\mathrm{M}=\%$ de milheto na dieta; $\mathrm{GG}=$ grupo genético; $\mathrm{M} * \mathrm{G}=$ interação entre fatores.

\section{CONCLUSÕES}

A substituição do grão de milho pelo grão de milheto em dietas com elevadas proporções de concentrado fornecidas para novilhos inteiros confinados não altera a composição químico-física da carne.

Tourinhos mestiços com predominância genética zebuína, alimentados em confinamento com dietas com elevada proporção de concentrado, apresentam carne com similares características físico-químicas que novilhos inteiros com predominância genética europeia, exceto para o grau de marmoreio que é menor.

\section{AGRADECIMENTOS}

À FAPEG pela bolsa de doutorado concedida ao primeiro autor.

\section{REFERÊNCIAS}

1. ANUALPEC. Anuário da Pecuária Brasileira, Instituto FNP, ed. 2012, 378 p.

2. Alves DD, Goes RHTB, Mancio AB. Maciez da carne bovina. Ciência Animal Brasileira.[Internet] 2005;6(3):135-149. Disponível em: http://www.revistas.ufg.br/index.php/vet/article/view/370/ $\underline{345}$

3. Menezes LFG, Restle J, Brondani IL, Silveira MF,
Freitas LS, Pizzuti LAD. Características da carcaça e da carne de novilhos superjovens da raça Devon terminados em diferentes sistemas de alimentação. Revista Brasileira de Zootecnia.[Internet] 2010;39(3):667-676. Disponível em: http:/www.scielo.br/pdf/rbz/v39n3/a28v39n3.pdf

4. Pacheco PS, Restle J, Silva JHS, Brondani IL, Pascoal LL, Alves Filho DC, et al. Composição física da carcaça e qualidade da carne de novilhos jovens e superjovens de diferentes grupos genéticos. [Internet] Revista Brasileira de Zootecnia. 2005;34(5):1691-1703. Disponível em: http://www.scielo.br/pdf/rbz/v34n5/26651.pdf

5. Hadlich JC, Morales DC, Silveira AC, Oliveira HN, Charulo LAL. Efeito do colágeno na maciez da carne de bovinos de distintos grupos genéticos. Acta Scientiarum. Animal. Science.[Internet] 2006;28(1):57-62. Disponível em: http://dx.doi.org/10.4025/actascianimsci.v28i1.664

6. Missio RL, Brondani IL, Freitas LS, Sachet RH, Silva JHS, Restle J. Desempenho e avaliação econômica da terminação de tourinhos em confinamento alimentados com diferentes níveis de concentrado na dieta. Revista Brasileira de Zootecnia.[internet] 2009;38(7):1309-1316. Disponível http://www.scielo.br/pdf/rbz/v38n7/v38n7a21.pdf

7. Missio RL, Brondani IL, Alves Filho DC, Restle J, Arboitte MZ, Segabinazzi LR. Características da carcaça e da carne de tourinhos terminados em confinamento, recebendo diferentes níveis de concentrado na dieta. Revista Brasileira de Zootecnia. [Internet] 2010;39(7):1610-1617. Disponível em: http://www.scielo.br/pdf/rbz/v39n7/a30v39n7.pdf

8. Hill GM, Newton GL, Streeter MN, Hanna WW, Utley 
PR, Mathis MJ. Digestibility and utilization of pearl millet diets fed to finishing beef cattle. Journal of Animal Science. [internet] 1996;74(7):1728-1735. Disponível em: http:/www.journalofanimalscience.org/content/74/7/1728

9. Müller L. Normas para avaliação de carcaças e concurso de carcaças de novilhos. 2. ed. Santa Maria: UFSM, 1987. 31p.

10. ASSOCIATION OF OFFICIAL ANALYTICAL CHEMISTS - AOAC. Official methods of analysis. 16.ed. Arlington: AOAC International, 1995. 1025p.

11. Lozano O, Theurer CB, Alio A, Delgado-Elorduy A, Cuneo P, Deyoung D, et al. Net absorption and hepatic metabolism of glucose, L-lactate, and volatile fatty acids by steers fed diets containing sorghum grain processed as dry-rolled or steam-flaked at different densities. Journal of Animal Science. [Internet] 2000;78(5):1364-1371. Disponível

em:

http://www.journalofanimalscience.org/content/78/5/1364. full.pdf + html

12. Immonen K, Puokanne E. Variation of residual glycogen-glucose concentration at ultimate $\mathrm{pH}$ values below 5.75. Meat Science. 2000b;55(3):279-283.

13. Immonen K, Ruusunena M, Hissa K, Puolanne E. Bovine muscle glycogen concentration in relation to finishing diet, slaughter and ultimate $\mathrm{pH}$. Meat Science. 2000a;55(1):25-31.

14. Lopes LS, Ladeira MM, Neto ORM, Paulino PVR, Chizzoti ML, Ramos EM, et al. Características de carcaça e cortes comerciais de tourinhos Red Norte e Nelore terminados em confinamento. Revista Brasileira de Zootecnia. [Internet] 2012;41(4):970-977. Disponível em: http://www.scielo.br/pdf/rbz/v41n4/20.pdf

15. Robergs RA, Ghiasvand F, Parker D. Biochemistry of exercise-induced metabolic acidosis. American Journal of Physiology. Regulatory, Integrative and Comparative Physiology. 2004;287(3):502-516.

16. Hocquette JF, Ortigues-Marty I, Pethick D, Herpin P, Fernandez $X$. Nutritional and hormonal regulation of energy metabolism in skeletal muscles of meat-producing animals. Livestock Production Science. 1998;56(2):115143.

17. Pösö AR, Puolanne E. Carbohydrate metabolism in meat animals. Meat Science. 2005;70(3):423-434.

18. Rocha Júnior VR, Silva FV, Barros RC, Reis ST, Costa MD, Souza AD, et al. Desempenho e características de carcaça de bovinos Nelore e Mestiços terminados em confinamento. Revista Brasileira de Saúde e Produção Animal. 2010;11(3):865-875.

19. Aferri G, Leme PR, Silva SL, Putrino SM, Pereira ASC. Desempenho e Características de Carcaça de Novilhos Alimentados com Dietas Contendo Diferentes Fontes de Lipídios. Revista Brasileira de Zootecnia. [Internet] 2005;34(5):1651-1658. Disponível em: http://www.scielo.br/pdf/rbz/v34n5/26647.pdf

20. Huff-Lonergan E, Lonergan SM. Mechanisms of water-holding capacity of meat: The role of postmortem biochemical and structural changes. Meat Science. 2005;71(1):194-204.

21. Abril M, Campo MM, Önenç A. Beef colour evolution as a function of ultimate $\mathrm{Ph}$. Meat Science. 2001;58(1):6978 .

22. Dave D, Ghaly AE. Meat Spoilage Mechanisms And Preservation Techniques: A critical review. American Journal of Agricultural and Biological Sciences. 2011;6(4):486-510.

23. Restle J, Keplin LAS, Vaz FN. Características da carcaça de novilhos Charolês, abatidos com diferentes pesos. Pesquisa Agropecuária Brasileira. 1997;32(8):851856.

24. Zhu X, Ruusunen M, Gusella M, Zhoua G, Puolanne E. High post-mortem temperature combined with rapid glycolysis induces phosphorylase denaturation and produces pale and exudative characteristics in broiler Pectoralis major muscles. Meat Science. 2011;89(2):181188.

25. Savell JW, Mueller SL, Baird BE. The chilling of carcasses. Meat Science. 2005;70(3):449-459.

26. Moggioni D, Prado IN, Zawadzki F, Velandia MV, Marques JA, Bridi AM, et al. Grupos genéticos e graus de acabamento sobre qualidade da carne de bovinos. Semina: Ciência Agrárias. 2012;33(1):391-402.

27. Osório JCS, Osório MTM, Sañudo C. Características sensórias da carne ovina. Revista Brasileira de Zootecnia. [Internet] 2009;38 Suppl 1:292-300. Disponível em: http://www.scielo.br/pdf/rbz/v38nspe/v38nspea29.pdf

28. Penea B, Asñdo C, Olleta JL, Civit D. Effect of ageing method, ageing period, cooking method and sample thickness on beef textural characteristics. Spanish Journal of Agricultural Research. 2008;6(1):25-32.

29. Oury M, Pierret P, Coulmier D, Dumont R. Eléménts de maîtrise de la couleur des viandes chez les bovins de race Charolaise. Productions Animales. 2009;22(2):131140 .

30. Ahemed SS, Josef K, Hans E, Peter F, Frieder JS. Effects of the dietary energy source on meat quality and eating quality attributes and fatty acid profile of Simmental bulls. Animal Research. 2006;55(4):287-299.

31. Kuss F, López J, Restle J, Barcellos JOJ, Moletta JL, Leite MCP. Qualidade da carne de novilhos terminados em confinamento e abatidos aos 16 ou 26 meses de idade. Revista Brasileira de Zootecnia. [Internet] 2010;39(4):924-931. Disponível em: http://www.scielo.br/pdf/rbz/v39n4/v39n4a29.pdf

32. Wheeler TL, Savell JW, Cross HR, Lunt DK, Smith SB. Mechanisms associated with the variation in tenderness of meat from Brahman and Hereford cattle. Journal of Animal Science. 1990;68(9):4206-4220.

33. Cattelan J, Menezes LFG, Ferreira JJ, Restle J, Brondani IL, Arboitte MZ, et al. Composição física da 
carcaça e qualidade da carne de novilhos e vacas de descarte de diferentes grupos genéticos submetidos a diferentes frequências de alimentação. Ciência Animal Brasileira. [Internet] 2009;10(3):764-775.Disponível em: http://www.revistas.ufg.br/index.php/vet/article/view/345 $\underline{0 / 5393}$

34. Miotto FRC, Restle J, Neiva JNM, Resende PLP, Lage $\mathrm{ME}$, Prado CS, et al. farelo de mesocarpo de babaçu (Orbygnia sp.) na terminação de bovinos: composição física da carcaça e qualidade da carne. Ciência Rural. 2012;42(7):1271-1277.

35. Bianchini W, Silveira AC, Jorge AM, Arrigoni MD, Martins DL, Rodrigues E, et al. Efeito do grupo genético sobre as características de carcaça e maciez da carne fresca e maturada de bovinos superprecoces. Revista Brasileira de Zootecnia. [Internet] 2007;36(6 Supl 0):2109-2117. Disponível em: http://www.scielo.br/pdf/rbz/v36n6s0/22.pdf

36. Pereira PMRC, Pinto MF, Abreu UGB, Lara JAF. Características de carcaça e qualidade de carne de novilhos superprecoces de três grupos genéticos. Pesquisa Agropecuária Brasileira. 2009;44(11):1520-1527.

37. Lima Júnior DM, Rangel AHN, Urbano AS, Maciel MV, Amaro LPA. Alguns aspectos qualitativos da carne bovina: uma revisão. Acta Veterinaria Brasilica. 2011;5(4):351-358.

38. Whipple G, Koohmaraie M, Dikeman ME. Evaluation of attributes that affect longissimus muscle tenderness in Bos taurus and Bos Indicus cattle. Journal of Animal Science. [Internet] 1990;68(9):2716-2728. Disponível em: http://www.journalofanimalscience.org/content/68/9/2716. full.pdf + html

39. Rubiano GAG, Arrigoni MB, Martins CL, Rodrigues E, Gonsalves HC, Angerani CN. Desempenho, características de carcaça e qualidade da carne de bovinos superprecoces das raças Canchim, Nelore e seus mestiços. Revista Brasileira de Zootecnia. [Internet] 2009;38(12):2490-2498. Disponível em: http://www.scielo.br/pdf/rbz/v38n12/a27v38n12.pdf

40. Pethick DW, Harper GS, Oddy VH. Growth, development and nutritional manipulation of marbling in cattle: a review. Australian Journal Experimental Agriculture. 2004;44(7):704-715.

41. Vaz FN, Restle J, Alves Filho,CC, Brondani IL, Pascoal LL, Vaz RZ, et al. Características de carcaça e da carne de novilhos filhos de vacas $1 / 2$ nelore $1 / 2$ charolês e $1 / 2$ charolês $1 / 2$ nelore acasaladas com touros charolês ou nelore. Revista Brasileira de Zootecnia. [Internet] 2002;31(4):1734-1743. Disponível em: http://www.scielo.br/pdf/rbz/v31n4/13735.pdf

42. Li C, Zhou G, Xu X, Zhang J, Xu S, Ji Y. Effects of marbling on meat quality characteristics and intramuscular connective tissue of beef Longissimus muscle. AsianAustralian Journal Animal Science. 2006;19(12):17191808.

43. Abrahão JJ, Prado IN, Perotto D, Moletta JL. Características de carcaças e da carne de tourinhos submetidos a dietas com diferentes níveis de substituição do milho por resíduo úmido da extração da fécula de mandioca. Revista Brasileira de Zootecnia. [Internet] 2005; 34(5): 1640-1650. Disponível em: http://www.scielo.br/pdf/rbz/v34n5/26646.pdf

44. Fernandes ARM, Sampaio AAM, Henrique W, Tullio RR, Oliveira EA, Silva TM. Composição química e perfil de ácidos graxos da carne de bovinos de diferentes condições sexuais recebendo silagem de milho e concentrado ou cana-de-açúcar e concentrado contendo grãos de girassol. Revista Brasileira de Zootecnia. [Internet] 2009;38(4):705-712. Disponível em: http://www.scielo.br/pdf/rbz/v38n4/17.pdf

45. Owens FN, Gill DR, Secrist DS, Coleman SW. Review of some aspects of growth and development of feedlot cattle. Journal of Animal Science. [Internet] 1995;73(10):3152-3172. Disponível em: http://www.journalofanimalscience.org/content/73/10/315 2.full.pdf + html 